to examine the provision of intensive care facilities in our hospital.

The fact that our figures, which may be verified with names and addresses, showed $22 \%$ more work being carried out than the figures available to the health authority showed, has obvious implications for the costing of our service.

Finally, surgeons often make judgments on the basis of available statistics for mortality for a procedure; the availability of up to date statistics from the unit concerned is an advantage in advising patients.

\section{CONCLUSION}

This audit helped to establish norms for our unit; it allowed us to recognise variations in results and to act when necessary to improve our results. The more the microcomputer was used for routine tasks in the department the easier it became to complete the audit. I suggest that a system such as ours should become part of the normal running of all surgical units.

My senior registrar Mr R Dale gave invaluable help in developing the current computer program. I thank the numerous house staff, registrars, and senior registrars who helped to collect the data; Mrs A Osborne, Miss E Tabor, and Miss Judith Bliss for entering the data into the microcomputer in the early stages of the project; and Mrs Ros Britton for her help with this manuscript.

\section{References}

1 Dunn DC, Dale RF. Combined computer generated discharge documents and surgical audit. $\mathrm{Br}$ Med F 1986;292:816-8.

2 Dunn DC. Incorporating a microcomputer in the surgical office. In: Coleridge Smith PD, Scurr $\mathrm{JH}$, eds. Microcomputers in medicine. London: Springer Verlag (in press).

3 Pollard SG, Friend PJ, Dunn DC. A microcomputer for general surgical audit and administration. In: Vicary FR, ed. Computers in gastroenterology. London: Springer Verlag (in press).
Pollard SG, Friend PJ, Dunn DC. microcomputer for general surgical audit and admist

4 Gough MH, Kettlewell MGW, Marks CG, et al. Audit: an annual assessment of the work and performance of a surgical firm in a regional teaching hospital. Br Med f 1980;281:913-20.

5 Gilmore OJA, Griffiths NJ, Connolly JC, et al. Surgical audit: comparison of the work load and results of two hospitals in the same district. BrMed f 1980;281:1050-2.

6 Prout WG, Blood PA. The establishment of a microcomputer-based diagnosis and operations index in the department of surgery of a district general hospital. Br $\mathcal{F}$ Surg 1985;72:48-51.

7 Broughton NS, Bunker TD, Ackroyd CE. The use of a microcomputer for inpatient audit in an orthopaedic department. Ann Surg 1985;67:259-62.

8 Irving $M$, Temple J. Surgical audit: one year's experience in a teaching hospital. $\mathrm{Br} \mathrm{Med} \mathcal{J}$ 1976;ii:746-7.

9 Glass RE, Thomas PA. Surgical audit in a district general hospital: a stimulus for improving patient care. Ann R Coll Surg Engl 1987;69:135-9.

10 Stern PH, Rubin EH. Computerised discharge summaries. Arch Phys Med Rehabil 1979;60:25-9.

(Accepted 8 October 1987)

\title{
Research Policy
}

\section{Glimpses of the National Institutes of Health II: review systems and evaluation}

\author{
RICHARD SMITH
}

The National Institutes of Health operate what must be the largest peer review system in the world to decide which grant applications they will support. The main difference with the system of the Medical Research Council is that the NIH system is more open: applicants are given detailed feedback on their proposals together with the chance to rebut the comments before a final decision is made and to appeal when they are turned down. The feedback is, however, anonymous, except in that the names of members of the committees are public knowledge.

The system "opened up" about 10 years ago to the accompaniment of dire predictions that the system would collapse or become enmeshed in argument. Neither prediction came true, but $\mathrm{Dr}$ Jerome Green, the director of the division of research grants, told me that comments on grants are now more detailed and careful and the whole process much more educational. It also must, he agreed, be more time consuming. Another important difference between the American and British systems is that a quarter of the members of one of the two committees that are part of the American process are lay people.

\section{The review process}

More than three quarters of the budget of NIH is spent on work done in outside institutions (mostly universities and medical

British Medical Journal, London WC1H 9JR

RICHARD SMITH, BSC, MB, assistant editor schools), and about 30000 grant applications are currently received each year. ${ }^{12}$ About 3000 of these are directed to other federal institutions-for instance, the Food and Drug Administrationand the rest are considered within NIH. About 22000 are considered centrally by the division of research grants, and the other 5000 are considered by the institutes themselves (this applies particularly to multidisciplinary and solicited applications and to applications for research training).

All applicants must be sponsored by a host institution, which is one method of ensuring that very poor applications are not submitted. The applications are long and detailed, and one researcher told me that it would take him about 10 weeks' work to complete an application. He did not think of this time as wasted because it was a time of hard creative thought that would be useful even if the application was turned down. The submitted applications are first looked at by health scientist administrators, who refer them to one or sometimes two of just under 100 initial review groups (more commonly called study sections) that cover all possible subjects. The administrators will send the applications back only if they are grossly incomplete, are not in English, or (an increasingly common reason) exceed the permitted 20 pages. The administrators have specific guidelines on which initial review group should see a particular application, but inevitably some applications would qualify for more than one group. Applicants can request that their proposals should be seen by particular review groups.

A review group has about 15-20 members, all of whom are researchers, and is chaired by a researcher. Figure 1 shows who these people are. A key person is the executive secretary of the group, who is not a practising researcher but an employee of NIH. Always the secretaries will have been researchers, and often they will have 


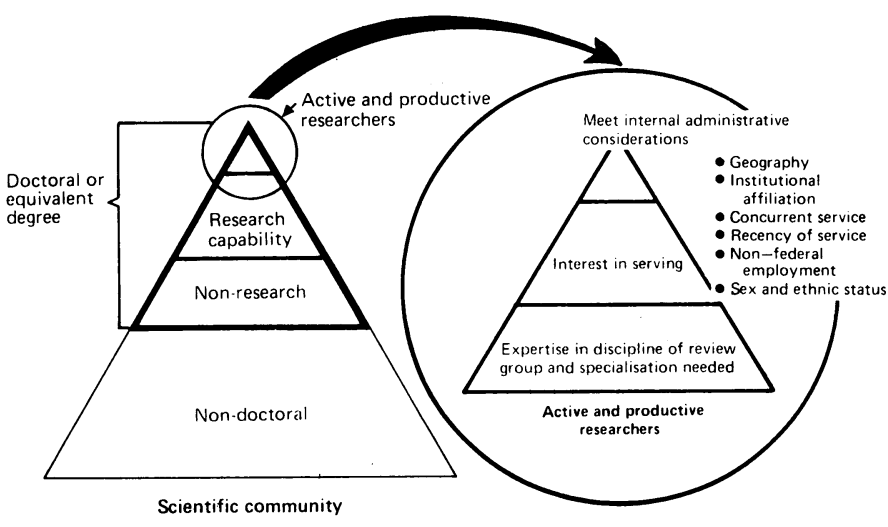

FIG 1 - Who are the peer reviewers of NIH!

worked in the subject of the review groups to which they are assigned. The secretary will allot each proposal to a primary and a secondary reviewer who are members of the review group. They must scrutinise the proposal especially carefully and will be expected to do things like look up references and previous papers published by the applicants. These reviewers will be selected because of their particular knowledge of the subject of the grant proposal, but when review groups cover subjects as broad as "endocrinology" the reviewers may not be sufficiently expert. In such circumstances the secretary may invite an opinion from an outside expert, who will be invited to join the review group and give his or her opinion: he can join in the discussion but cannot vote. Alternatively, one or more written expert opinions may be invited and passed to the primary reviewer. One researcher to whom I spoke was worried that despite these extra mechanisms the review groups were not broad enough and that people might be giving the primary opinion on a subject in which they were not sufficiently expert.

The review groups meet three times a year and consider about 75 proposals at a meeting that will last two to three days. Members of the group will have received all the papers in advance, and each member will have scrutinised about 10-15 in detail. The group spends about half an hour on each proposal: the primary reviewer will spend about 10 minutes summarising the proposal and mentioning its strong and weak points; the secondary reviewer will briefly give his opinion; and the group will then ask for clarification from the primary and secondary reviewers and give their opinions. After about 20 minutes the primary reviewer will sum up and give his recommendation. He will also say whether he thinks that the proposal should be strongly or mildly supported-and may even suggest a particular score. The group then votes on whether to approve, disapprove, or defer the proposal; it may defer for more information. If more than two people vote for disapproval the group must include a minority report in the "pink sheet," which summarises the proposal and gives strong points, weak points, and a recommendation. If a grant is approved the committee secretary gives a priority score between 1 (the highest) and 5 (the lowest): the score is then averaged and multiplied by 100 .

\section{THE NATIONAL ADVISORY COUNCIL}

This score is added to the pink sheet, which is sent to the grant applicant and to the national advisory council of the institute that is most likely to fund the proposal. (Some review groups send all their proposals to the same institute; others may send them to various institutes.) The national advisory councils are composed three quarters of researchers and one quarter of lay people with a special interest in the work of the institute-for instance, the mother of a haemophiliac boy, or the secretary of a self help group for those caring for demented people. The council will not change the score of the review group but may make a recommendation that one with a lowish score be funded because the council thinks that the work has special importance or relevance. The council's recommendations are forwarded to the director of the institute, and he takes the final decision on funding. He can only, however, fund a proposal that has been approved by the advisory council, and it is this restriction that prevents political interference.

Once he receives his pink sheet the grant applicant may if he wishes submit a letter of rebuttal that will be seen by the advisory council at the same time that it considers the recommendation from the review group. $\mathrm{He}$ or she might argue that the wrong review group had seen the proposal or that the group had contained somebody known to be biased against him or her. Alternatively, the applicant might withdraw the proposal and resubmit it. This happens commonly, and about a quarter of grant applications are resubmissions, which is one explanation of the high approval rate (now about $90 \%$ ). Rebuttal letters are submitted in about $10 \%$ of cases. NIH staff will comment on the letters, and in only about $1-2 \%$ of cases will the letters lead to the proposals being put through the review process again. NIH also has a formal appeal mechanism. Such an appeal must be sponsored by the applicant's host institution. It is submitted to the director of the institute, who may refer it back to the national advisory council. (Thus the appeal is not to a "higher court" but to the same court.) Such appeals arise only about 10 times a year and are rarely successful; it is easier (and quicker) simply to resubmit an improved version of the application.

\section{PROBLEMS}

One problem with this system is that it takes an enormous amount of work: NIH has estimated that members of review groups must do about two months' work a year-and yet they are paid for only nine days. Another problem is that members of review groups worry that their own grant applications will not do well because they cannot be reviewed by the group of which they are a member-and so must be submitted to a group that may not be the natural home of the research. NIH has done a study that has allayed these fears: the applications of those sitting on review groups are more likely to be funded than those not on the committees (which is to be expected because members are selected for their excellence) and just as likely to be funded as those who were on the committees (and whose applications can now go back to those committees). Another worry about review groups is that they may become too "old boyish," but about $85 \%$ of new members have never served on a committee before, and there are rules that stop people staying on committees too long and reappearing too quickly.

\section{GRADE CREEP}

The biggest worry of those running NIH's peer review system is "grade creep" - the way that mean priority scores have been climbing steadily (fig 2). Researchers might argue that this creep reflects rising standards of science, but most observers think that the cause of creep is researchers wanting to protect their subjects: if the priority scores are high grants in their subject are more likely to be funded. Furthermore, institutes are keen to have high priority scores because then they can tell congress that they are funding down to a high score, which carries the double message that the science they are supporting is of high quality (perhaps higher than that of other institutes) and that they should be given more money to fund further down.

Ultimately this rise towards the asymptote of 100 will render the scoring system useless. Another difficulty is that the mean scores vary between review groups-for instance, scores in basic sciences tend to be higher than in subjects like epidemiology. In some ways this makes sense because for basic biological sciences the science can be "harder" than for epidemiology and also the grants tend to be smaller and shorter; with an animal study, for instance, you can get somewhere quickly and cheaply and bale out or change direction if the work is not proving fruitful, whereas with an epidemiological study you may be locked in to years of data collection. The grant 
proposal does therefore need to be of a very high standard to deserve funding, but the institutes want to maintain a broad range of work and so have to find a way of standardising scores.

The first method used was to standardise scores after two meetings of the review groups, but the method now used is to give a priority score and a percentile: a grant might thus have a high priority score but still be low in the percentile rankings.

Another problem thrown up by grade creep is that one member of a committee may be able "to blackball a grant" by voting it a very low priority score when everybody else is voting it a high one. One way to deal with this is to exclude outliers or to bring them within two standard deviations of the mean score, and another way-the one adopted by NIH-is to talk to the person who gave such a low score and see if his reasons are good. (If they are his score counts, but he is warned that he should give his reasons in the - open discussion so that the executive secretary will know why he has given such a low score. One of the jobs of the secretary is to see that the score reflects the discussion.) If the reasons for giving an outlying low score are not good his score may be struck out. Sometimes the decision on what to do with outlying scores will be long and complicated.

\section{Reasons for failure of clinical research}

NIH conducts a continuing evaluation of the validity of its review procedures and between 1960 and 1971 did three analyses of the deficiencies of proposals that were not approved. ${ }^{3}$ A 1971 study of 826 applications that were not approved showed shortcomings in $99 \%$ in the proposed experimental approach, in $60 \%$ in the qualifications of the investigator, in $4 \%$ in the nature of the problem, and in $23 \%$ in the research environment. ${ }^{3}$

A more recent study has looked particularly at why proposals for clinical research are more likely not to be approved than proposals for basic research. ${ }^{3}$ Between 1976 and 1981 only $63 \%$ of over 24000 clinical research applications were approved compared with $74 \%$ of over 51000 applications for basic science. The proportion awarded was, however, similar-39\% for the clinical applications and $40 \%$ for the applications in basic science.

The study looked at 256 clinical applications from 1981 that had been either disapproved or given a low priority score. The researcher, Cuca, identified eight sorts of shortcomings (table) and found that the mean number of shortcomings in each proposal was $2 \cdot 8$. Deficiency in methodology was the commonest shortcoming $(66 \%)$ followed by a poor hypothesis $(47 \%)$. Cuca's study did not look at applications for basic science, but a comparison with the previous studies of shortcomings (which actually used different classifications of shortcomings, making comparison difficult) showed that the reasons for disapproval were similar for both sorts of applications.

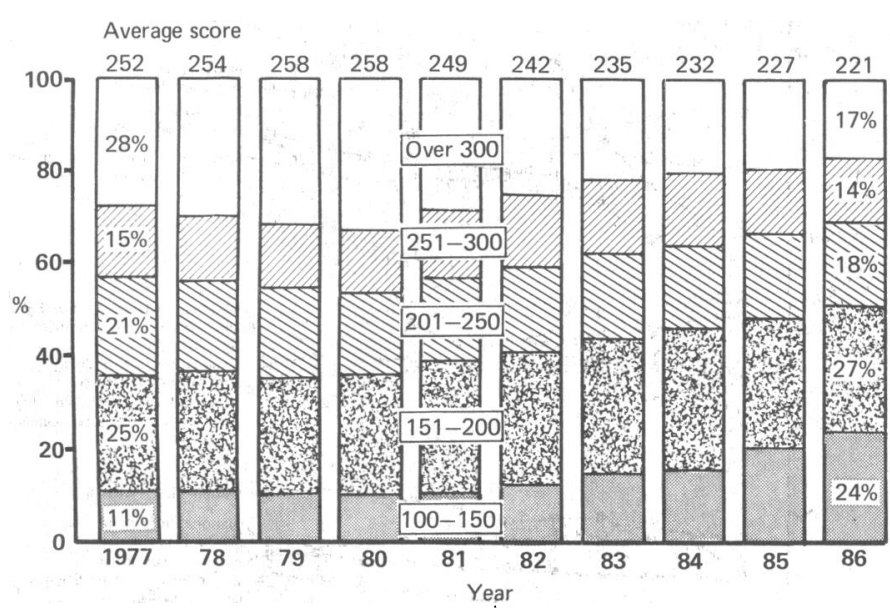

FIG 2-Distribution of priority scores of project applications submitted to the National Institutes of Health, 1977-86. The highest priority score is 100 and the lowest 500.
Shortcomings of clinical grant applications not approved or poorly rated by the National Institutes of Health

\begin{tabular}{lc}
\hline & $\begin{array}{c}\text { No (\%) of } \\
\text { papers } \\
\text { showing that } \\
\text { shortcoming }\end{array}$ \\
\hline Shortcoming & $120(47)$ \\
\hline $\begin{array}{l}\text { (1) Research problem: hypothesis-ill defined, lacking, faulty, diffuse, } \\
\text { unwarranted }\end{array}$ & $77(30)$ \\
$\begin{array}{l}\text { (2) Research problem: significance-unimportant, unimaginative, unlikely to } \\
\text { provide new information }\end{array}$ & $103(40)$ \\
$\begin{array}{l}\text { (3) Experimental design: study group or controls-inappropriate composition, } \\
\text { number, or characteristics }\end{array}$ & $168(66)$ \\
$\begin{array}{l}\text { (4) Experimental design: technical methodology-questionable, unsuited, } \\
\text { defective }\end{array}$ & $104(41)$ \\
$\begin{array}{l}\text { (5) Experimental design: data collection procedures-confused design, } \\
\text { inappropriate instrumentation, timing, or conditions }\end{array}$ & $80(31)$ \\
(6) Experimental design: data management and analysis-vague, \\
unsophisticated, not likely to provide accurate and clearcut results \\
$\begin{array}{l}\text { (7) Investigator-inadequate expertise or familiarity with literature in the } \\
\text { research area, poor past performance or productivity on an NIH grant, } \\
\text { insufficient time to be devoted to project }\end{array}$ & $43(17)$ \\
$\begin{array}{l}\text { (8) Resources-inadequate institutional setting, support staff, laboratory } \\
\text { facilities, equipment, or personnel; restricted access to appropriate patient } \\
\text { population; insufficient involvement or collaboration of colleagues and } \\
\text { coinvestigators }\end{array}$ & $9(4)$ \\
\hline
\end{tabular}

No reason could thus be found for why clinical research does poorly compared with basic research, but NIH is concerned and "the issue continues to be a topic of concern and study."

\section{Requesting grant applications}

Most of NIH's money is spent on investigator initiated research, but it also commissions research and has directed research going on in its laboratories. Bodies that fund research naturally want their research to be relevant and of high quality, and sometimes these two demands conflict: the best research may not be the most relevant to medicosocial needs, and research that is relevant may not be of high quality. NIH has evolved a system of requesting applications for work on a particular subject in an attempt to generate research that is high in both relevance and quality. Dr Barbara Packard, director of the office of program planning and evaluation of the National Heart, Lung, and Blood Institute, described to me the system that the institute has developed for requesting relevant research.

The process revolves around five advisory committees made up of scientists and clinicians, which meet two or three times a year. At their first meeting in the yearly cycle the committees consider about 10 to 30 ideas for research that have been generated by many different sources. The ideas come from committee members themselves, from workshops and conferences, and from members of the institute staff, who are competitive in trying to spot new opportunities. Importantly, they also come from extensive communication with many self help groups for diseases of the heart, lung, and blood and from professional organisations-indeed, from anybody who might have something interesting to offer.

At its first meeting of the year the advisory committee will discuss these proposals, decide which are worth considering further, and then set up small working groups that will consider in detail the need for the research and the feasibility of reaching clear goals. At the second meeting each proposal will be debated and eventually ranked. The committee will also consider existing programmes and consider which might be discontinued. (All grant giving bodies seem to find it easier to discuss what should be done rather than what should be stopped.)

The proposals from the advisory committees will be passed up through the executive committees of the divisions and eventually presented to the director as a package of research that the division would like to see implemented. The director then integrates the packages of the divisions, bearing in mind the need to balance work on different topics and clinical and basic research. He will also consider what is already being done and what can be afforded. There are two main criteria for undertaking an initiative. The first is the importance of the goals: the size of the problem; the state of the science, medical practice, and public health in relation to the 
initiative; whether the anticipated results might provide entirely new concepts and approaches, importantly advance knowledge, or definitively settle an important question; the likelihood of achieving the results; timing; and the resources that will be needed. Importantly, the "opportunity costs" are considered. The second main criterion is that the institute needs to solicit an application rather than simply wait for an unsolicited application or announce that it is interested in the general area. Using these criteria the director whittles about 40 possible initiatives down to about 30 .

The director will pass his recommendations to the national advisory council, which will comment on them and then approve or occasionally disapprove them. Depending on how much money is available some requests for applications will then be released while others are held. Some initiatives may be so specific that the work will be contracted out. Once applications are received in response to a request they are put through the same review process as unrequested applications.

\section{Evaluation of requests for applications}

Dr Carl Roth, the chief of the program analysis and evaluation branch at the National Heart, Lung, and Blood Institute, has assessed the quality and effectiveness of requests for applications using various indicators. ${ }^{4}$ The first thing that his analysis showed was that more than half of the requests were for basic research. Figure 3 shows the proportion of applications that were approved compared with the proportion of standard investigator initiated grants that were approved: overall from 1975 to $1986,77 \%$ of the requests for applications and $67 \%$ of the standard grants were approved. The percentage awarded was almost exactly the same-

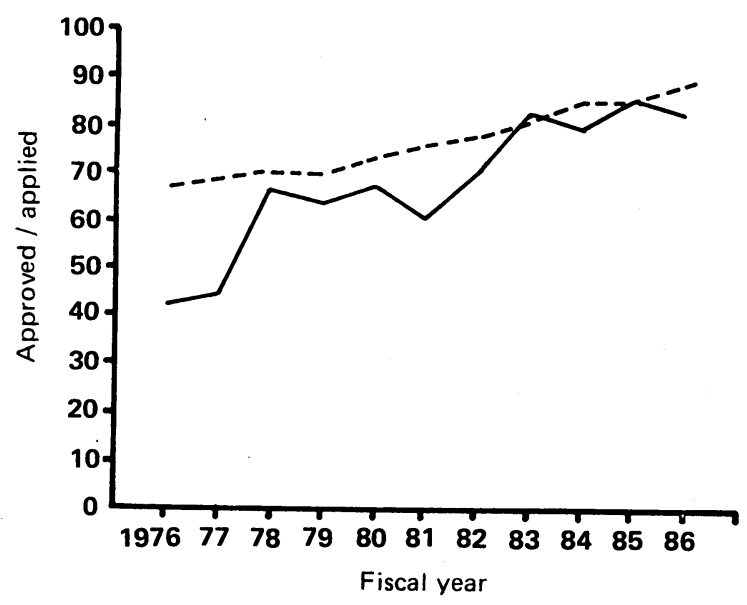

FIG 3-Proportion approved of grant proposals submitted to the National Heart, Lung, and Blood Institute in response to a request (solid line) and of those that are investigator initiated (broken line), 1975-86.4

$33 \%$; the similar rate of awards in the face of a lower rate of approval for requests for applications presumably reflects the fact that the grant committees thought the proposed projects more important. The last paid priority scores of the two sorts of grants were, however, "within the same general range."

Roth also did a bibliometric analysis of the 152 grants that were supported from 23 selected requests for applications between 1979 and 1982. No publications were found for 16 of the grants, but the others produced 717-just under five for each grant. A citation analysis of those papers published in 1980 and 1981 showed that they were cited 20 times, which compares favourably with the estimate that over seven years (thus a longer period) the average paper resulting from a project supported by the National Heart, Lung, and Blood Institute would be cited 3.8 times.

Roth's analysis thus shows that the National Heart, Lung, and Blood Institute can decide what topics it wants studied and then

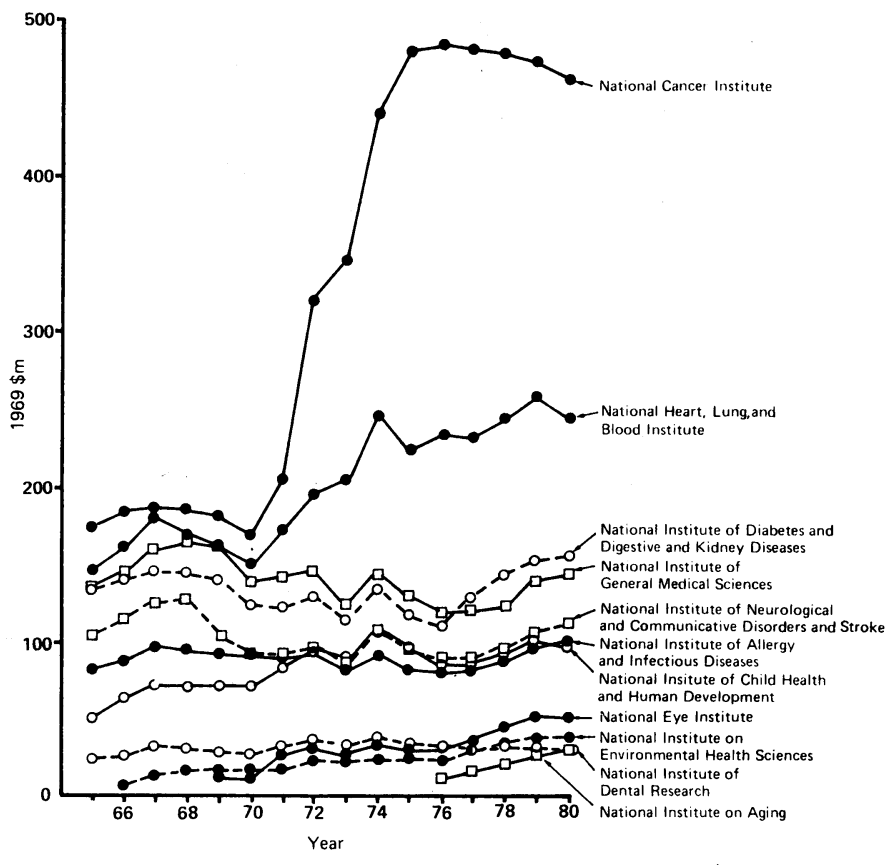

FIG 4-Papers acknowledging support from the National Institutes of Health appearing in 275 scientific journals.

generate research that is of just as high a quality as research that is initiated by the researcher himself. Indeed, the appreciably higher citation rate suggests that the research generated by request may be of greater importance.

\section{Evaluation at NIH}

NIH devotes much more time and energy than the MRC evaluating what it is doing. I came away from my visit laden with books of data and evaluation. Some of the people I met were cynical about whether this evaluation had much value and caused anything to change, but most think that spending such vast amounts of government money without evaluation would be wrong. Most of the evaluation is based on bibliometric evaluation, and much of it is

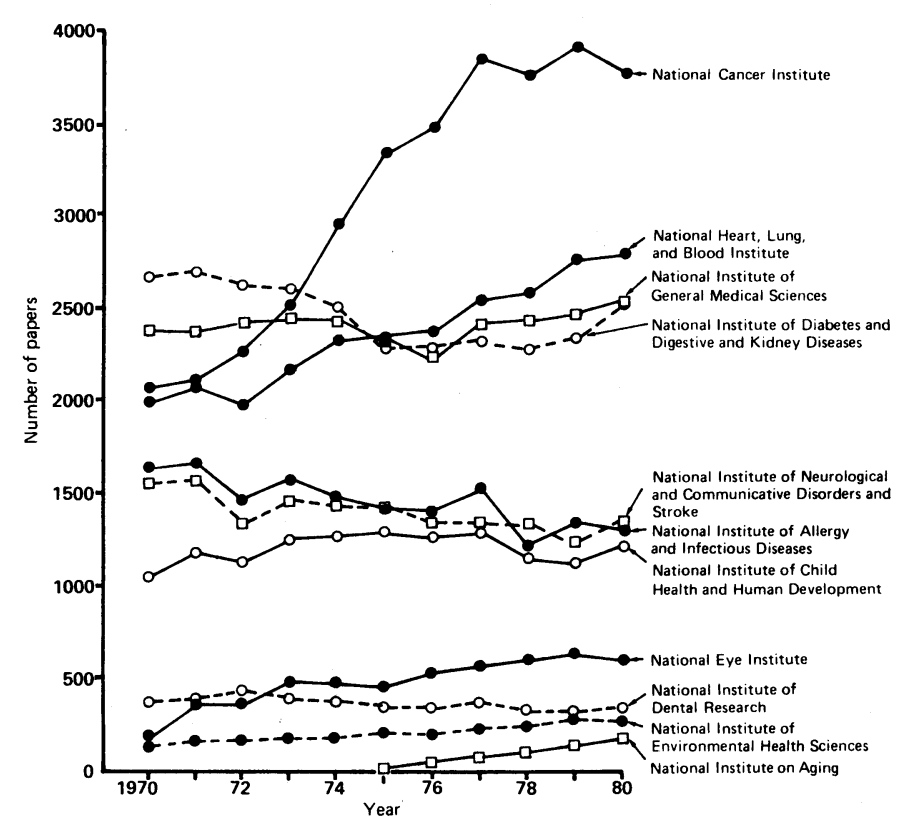

FIG 5-Expenditure of the National Institutes of Health in constant 1969 dollars. 
done by Computer Horizons, Inc and its president, Francis Narin. ${ }^{56}$ Dr Narin is now a regular transatlantic passenger as various British bodies funding research are becoming very interested in what he has to offer.

One of the crudest evaluations and yet the one that packs the biggest punch is the number of Nobel prize winners that have been supported by NIH grants-currently not far under 100 . Some of these may have had rather tenuous links with $\mathrm{NIH}$, but that does not prevent the institutes from having a changing board showing the current total just outside one of the canteens.

Bibliometric analysis offers more comprehensive analysis and figure 4 shows the number of papers acknowledging support from the various institutes published in 275 scientific journals. ${ }^{5}$ Figure 5 shows the funding of the institutes, and the correlation between funds from 1965-77 and publications three years later is very high $(r=0.9) .{ }^{5}$ The effects of Nixon's war against cancer can be clearly seen, and the correlation between the figures shows that money will produce papers even if it won't cure cancer.

One measure of the citation quality of an institution is its "top decile performance" - the percentage of an institution's papers that appear in the top $10 \%$ of cited papers in the relevant discipline. ${ }^{56} \mathrm{An}$ average institution would expect obviously to have $10 \%$ of its papers in the top decile. In fact NIH's intramural programme has $26 \cdot 1 \%$ of its papers in the top decile and the extramural programme has $6.3 \%$, whereas all United States and United States supported research has $11 \cdot 7 \%$, and United States papers that do not acknowledge support (many of them observational papers by individual physicians) have $3.9 \% .{ }^{6}$ As Narin writes, "By any standards the citation performance of the NIH intramural programme is truly outstanding and that of the extramural programmes demonstrably excellent." Figure 6 shows for the 21 subjects in which NIH is most active the percentage of papers it supported that are in the top decile of cited papers: in every case it is higher than $10 \%$, showing the high quality of the work. ${ }^{5}$

\section{Conclusions}

Much of what goes on at NIH I did not have time to consider, but my explorations allowed me to bring back some messages that I think are relevant to Britain in general and to the MRC in particular. Firstly, I think that the MRC should consider opening up its review procedures much more, providing feedback to applicants and allowing them to interact with the grant committees. It might also allow appeals. Secondly, the MRC and other funding bodies should think hard about exploring ways of actively promoting research that is suggested by the public and others in topics that are currently underresearched: the evidence from the United States is that such research can reach as high a standard as that which is initiated by

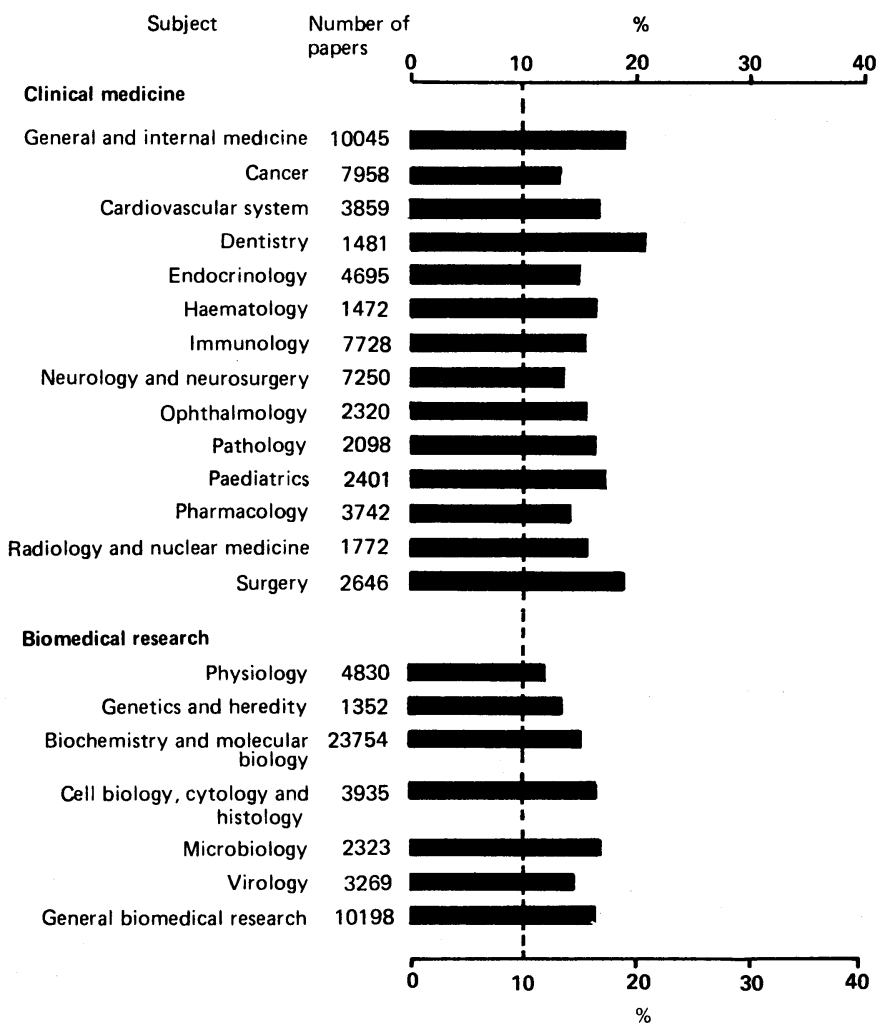

FIG 6-Percentage of papers supported by NIH that are in the top decile of cited papers for the 21 subjects in which NIH is most active.

those who will do the research. Thirdly, the MRC and other funding organisations need to think much more about evaluation, not just to make sure that their money is well spent but also to produce data to convince governments and others of the quality and usefulness of what they are doing.

\section{References}

1 National Institutes of Health. NIH data book 1986. Bethesda: NIH, 1987.

2 National Institutes of Health. NIH peer review of research grant applications. Bethesda: NIH, 1987. 3 Cuca JM. NIH grant applications for clinical research: reasons for poor ratings or disapproval. Clin Res 1983;31:453-63.

4 Roth CA. An assessment of NHL BI requests for applications. Physiologist 1987;30:35-9.

5 Gee HH, Narin F. An analysis of research publications supported by NIH 1973-76 and 1977-80. Bethesda: NIH, 1986.

6 Narin F. Bibliometric techniques in the evaluation of research programs. Science and Public Policy 1987 April: $99-106$

\section{MATERIA NON MEDICA}

\section{Your syntax will find you out}

A recent description of someone as being an "obsessional grammarian" reminded me of Miss Johnson.

Miss Johnson taught English in my Rhodesian (then) high school. She had come out from England, many years previously, precisely for this purpose. She rather despised colonials, who had to be taught the rudiments of civilisation. The rudiments of civilisation, in her view (and she may well have been right), equated with the rudiments of English grammar.

Unlovely and unimaginative, always dressed in a droopy white cardigan quite unnecessary in that climate but worn to protect her from the barbaric African air, she drilled us with all the charm of a sergeant major. There was a correct way and an incorrect way. No allowances were made for flights of fancy, pretty images, or startling revelations. She spoke slowly and clearly and carried a big fly swat, a well recognised symbol of authority in Africa. Miss Johnson's fly swat was a heavy piece of doubled webbing, wielded constantly for emphasis and brought down far from gently on the person of any child who failed to parse a sentence correctly. Miss Johnson would have considered the European Court of Human Rights, and its stand on corporal punishment, a communist plot.

We detested her, as only schoolchildren can detest tyrannical teachers, and we exacted spiteful revenge. We mocked her "Oxford" accent, we adopted slovenly colonial tones, and we larded our speech with Afrikaans and Sindebele words whose meanings she did not dare to contemplate. The ultimate power, however, was hers. We all learnt, very fast, the one unbreakable rule of English grammar: it is wrong if it brings Miss Johnson's fly swat down on your head.

How I remember those hot and hated afternoons, when everything we did seemed irrelevant; and how grateful I am for them now, for the pleasure I get from elegant and well constructed prose. And, indeed, even for the perverse pleasure of spotting, in the reams of administrative bumf which land uninvited on my desk, the split infinitives and malpositioned clauses.- 